\title{
The Risk of Trained Employee Loss and the Avoiding Strategies
}

\author{
Yingzhen Zhou \\ Economics and management college of Three Gorges \\ University \\ Yichang, China \\ zhouyz@ctgu.edu.cn
}

\author{
Xinghui Yang \\ Economics and management college of Three Gorges \\ University \\ Yichang, China \\ yangxinghui1115@sina.com
}

\begin{abstract}
Training is designed to improve the staff's operational skills and overall quality. It can enhance the efficiency and the overall capacity of enterprises. The risks and benefits of training are co-existent. As the main risk bearers, enterprises should correctly understand the training, and actively deal with the loss of trained staffs after the training. This article analyzed the motivation of loss of trained employee by identifying the types of loss risk and proposed several methods to avoid it with the purpose of improving the effectiveness of training.
\end{abstract}

Keywords-training; loss risk; motivation; risk-averse measures; training benefits

\section{INTRODUCTION}

As the most critical resource in the business, human resources play a subjective initiative to create economic benefits through deliberately and purposefully utilizing various production factors in production activities. Human resources are deprived from individual workers, flowing with the mobilization of individual workers. Due to the subjective initiative and mobility, investment in human resource training are risky to some extent. Being the active resources of organizations, well-trained employees are key capital of organizations. The loss of trained employees is not only harmful to the growth and development of enterprises, but also affects individual employees. Therefore, to avoid the risk of trained employee is particularly important.

\section{THE IDENTIFICATION OF THE LOSS RISK OF TRAINED EMPLOYEE}

Enterprises utilize available resources and invest certain amount of manpower, material and financial resources to carry out the training program, and training benefit is uncertain. In the next few years, a corporate training investment risk is constituted from the unbalance in which benefits from the enterprise training can not compensate for the cost of the investment. The loss of trained employee will increase the training investment risk. Specific features are shown as: disinvestments in training, increases in the financial burden and competitive pressures of enterprises, weakening the corporate core competitiveness and training enthusiasm and so on.

\section{A. Disinvestment in Training}

The training investment are constituted by the various inputs carried out in the training program, such as lecturers' salaries, payments for training sites and equipments, the personnel consumption of support department for training programs, trained employees' income during the training period. Trained employee loss is not the issue whether or not the training achievements are converted in time and successful. Neither is the issue of appreciation of human capital. The loss of labors - human resources carriers - directly stifles the possibility of investment return in training, resulting in the disinvestments in training programs.

\section{B. Increase of Financial Burden}

The loss of trained employee will increase the financial burden. First, the recruitment of new employee is needed after the loss of trained employee. Recruitment, selection, hiring and training new comers consume enterprise's human, material and financial resources. Second, new employee will take time to familiarize with the job and adapt to the working environment before they can create value for enterprises. In order to help new employees get accustomed to their positions better and more quickly, management costs, to some degree, often show an increasing tendency. Third, as new comers have few operational skills as well as low operational proficiency, they are more likely to waste raw materials and produce unqualified products, which directly results in increasing the cost of production, and therefore have a negative impact on economic performance of enterprises. Fourth, the fact that the new employees produce no more value per unit of time than their wages paid will cause an increase of overall costs.

\section{Increased Pressure in the Competition}

Even though employees, after training, have strengthened their operational skills, operational proficiency, vocational competence and comprehensive quality, they, if lack of sense of belonging, are very likely to be tempted by the olive branch other companies of same kind stretch out with better treatment, welfare and turn to work for them, or establish their own businesses as potential competitors. It will undoubtedly intensify difficulty in market competition. Moreover, loss of technicians and core staff with enterprises' technical ideas and internal confidentiality will pose a potential threat to their survival.

\section{Degeneration of Enterprises' Core Competitiveness}

Heavier financial burden will cause damage to corporate price advantage, that is, unduly huge internal consumption will harm competitive advantage of enterprises. Drain of trained employees will augment difficulty in protection of confidential technology, that is, loss of trained employees, especially senior 
management and technicians, will increase risk of leakage of corporate secret and core techniques. Every company has its unique corporate culture, development history, management experience, core techniques and operational skills. These competitive advantages, which cannot be duplicated and imitated in the short term, comprise the corporate core competitiveness. Drain of senior management and top technicians means that more people could get access to the corporate code of business and technological ideas, which will spawn higher difficulty in protection of specialistic techniques, higher risk of leakage of information and techniques, as well as higher threat to the corporate core competitiveness.

\section{E. Negative Influence on Corporate Enthusiasm for Training}

Enterprises improve employees' skills and overall quality by training and expect them to yield better performance in business and create more profits. However, drain of trained employees, as a result of human's psychological and physiological complexity, renders enterprises which are subject to training risk afraid of training. They fear that their training "fruit" may be snatched by their competitors, to say nothing of other potential damage to themselves. Without training, necessary adjustment to outside environment can't be achieved and corporate and individual needs for development can't be met, but loss of trained employees fails to benefit training enterprises. In this sense, enterprises are always on horns of dilemma. The enterprises which choose to do training reluctantly would cut in large amount of their spending (human, material, financial resources and attention) on training after their enthusiasm for training is badly stricken by loss of their trained employees, which has huge negative influence on training effect and then quickens flow of employees. In the vicious circle, corporate enthusiasm for training will become lower and lower.

\section{AN ANALYSIS OF CAUSES FOR DRAIN OF TRAINED EMPLOYEES}

Loss of trained employees imparts a complicated feeling to enterprises when it comes to training. What is it that leads to drain of trained employees as their personal skills are, to some degree, ameliorated in training?

\section{A. In Corporate Terms}

1) Premature training:Training goal centering on future development of the industry can not only improve employees' overall quality but adjust the content of training to changes in the market. Premature content in training, however, means that it will take longer time to come into fruition. Under current conditions in business world, premature training receives a smaller platform to show its effect, that is, training benefits cannot be observed clearly in a short period of time. If the training fails to come into fruition in time, on the one hand, corporate incentive will come relatively late, which will discourage employees' enthusiasm for training. On the other hand, employees will get little sense of satisfaction and identity and then intend to resign. The fact that employees fail to feel any progress after training will, to some degree, prompt staff turnover.
2) Insufficient incentives:Labors, as transmitters of labor force with personal initiatives, play an important role in achievement of training goals. Insufficient incentives in training influence not only training goals fulfillment both qualitatively and quantitatively but employees' enthusiasm for training, and indirectly motivate trained employees to resign. Insufficient incentives always cause a shrinkage in employees' sense of identity for a great deal of factors such as treatment, future development, interpersonal relation, corporate prospect and culture. They perceive a threat to their interests and leave for another companies out of self-defence instinct.

\section{B. In Individual Terms}

3) Lack of loyalty:Employees lacking in necessary loyalty and sense of belonging always take chance of training provided by enterprises as a springboard. On the one hand, if there appear an olive branch reached out by other enterprises, trained employees, with better skills and poor loyalty, tend to move to those enterprises with better treatment and welfare as well as more room for development. On the other hand, employees, driven by egoism, are more likely to look for enterprises with more preferable treatment, more beneficial environment and more promising future. Thus, scarcity of loyalty renders employees more prone to be induced by external temptation and internal tendency, which will result in habitual drain of staff.

4) Fulfillment of individual value:Employees in new era focus on fulfillment of individual value, hoping to challenge themselves continuously and gaining sense of achievement in jobs. Rigid work schedule get them tired. They are keen to apply what they have learned in training into their work and try to make breakthroughs and new innovations. Employees normally attempt to make a change as long as they can't get a platform to show their performance.

5) Marital and family conditions of laborers:As members of social groups, laborers are indispensably connected to families, organizations and other fields. Hence, their thoughts and actions are influenced by family and social factors. After training, there is probably a change in employee's treatment and workplace. Employees must take marital and family conditions into consideration and therefore, become very prudent about change in position or workplace. Given the workplace remains unchanged, employees tend to take their family responsibility as top priority. When changes in workplace occur which involves disturbance of time employees can spend with their families and friends, they will contemplate whether to resign or not according to the realty.

\section{In Social Terms: Lack of Punishment Mechanism}

In our society, no tough action is taken to punish unreasonable flow of trained employees, and there's no law drawing a line of demarcation between the reasonable flow of human resources, trans-sector flow and the unreasonable ones. Lack of relevant law spawns casualness of staff flow. Even though in the case of breach of labor contract or violation of training contract, the trained employees who leave from 
training companies only receive material punishment which has no deterrent effect and leads them to think that they can go merely by paying liquidated damages.

Morality, as an ideology, sets a higher standard for behaviors of social members, even if the standard is not as compulsorily binding as laws. Nevertheless, there's no moral constraint on employee flow in Chinese society at present.

\section{AVOIDING RISK OF TRAINED EMPLOYEES DRAIN}

Enterprises face various uncertainties when investing in training. The stakeholders and the beneficiaries of corporate investment in training may be different. Based on the idea of coexistence of investments and benefits, we come up with several measures to avoid loss of trained employees in corporate, individual and social terms respectively.

\section{A. In Corporate Terms}

1) Reinforce employees' education on professional ethics:Enterprises are supposed to devote much attention to their employees' education on professional ethics in the way of improving their awareness of code of conduct and professional moral standard, cultivating employees' sense of identity for corporate philosophy, culture and values in order to develop corporate spirit. Only by establishing great professional aspiration can employees' enthusiasm for their jobs and pursuit of professional expertise be inspired. Education on professional ethics can enhance not only employees' loyalty but corporate cohesion. Employees of high loyalty and sense of belonging are loyal to and dependent upon their enterprises. Therefore, they will do their utmost to protect their enterprises.

2) Sign training contracts:Before training, enterprises ought to sign training contracts with employees. The training contract stipulates that enterprises provide training opportunities for employees, in return, employees must work in the enterprises for a certain period of time after training. If employees violate their contracts, they will assume relevant legal liability which should be more than the benefits they receive from training. The punishment contains not only material compensation but constriction on trained employees' behaviors after resignation. For example, employees of the key positions can't work for other companies of the same kind in certain years, otherwise, training companies have right to prosecute.

3) Establish splendid corporate culture:Developing corporate culture, to some degree, amounts to construction of employees' values. A splendid corporate culture is universally accepted and followed by employees, which is conducive to survival and development of the whole enterprise. A good corporate culture should cover the characters of the corporation and adjust itself to the current and future trend of development by conducting the environment scanning. In order to guarantee value orientation of corporate culture, it must be applied into construction of corporate mechanism and senior officials must behave themselves as a leading sample. A splendid corporate culture is bound to gain general support from employees, which will undoubtedly strengthen corporate cohesion. Thus, employees who are attracted by and accept corporate culture will not leave the corporation easily.

4) Create superb stimulative mechanism:To some degree, the utilization efficiency of human resource capital constantly rises after training. We can carry out remunerative stimulus according to employees' contribution. And take wage by seniority into personalized remuneration through implementing the practice of one post with different wage levels on the basis of equal pay for equal work. One principle, however, should be observed: keep the coherence of assessment standard for assessing different objects. Flexible wage proportionate to individual contribution and fruition rate of training is also a good measure. Besides, dividend mechanism such as annual dividend, option incentive and equity incentive is of same effect in maintaining employees. After training, enterprises can enhance trained employees' satisfaction with their jobs by promotion, reserved cadres program and so on to retain them.

\section{B. In Individual Terms}

1) Strengthen Enthusiasm for Training:Employees must recognize the importance of training and admit spontaneously they are also beneficiaries of corporate training. They should develop right understanding of training which, as a measure of human resource development, is one form of welfare for mutual development of employees and enterprises. Employees are supposed to be more active in training and later application, and regard training as a corporate investment in staff. In this sense, enterprise is investor as well as beneficiary of training.

2) Improve Corporate Culture Spontaneously:Corporate culture consisting of values generally accepted by employees epitomizes core corporate ideas. It continues to develop along with the development of the enterprise and advance as internal and external environments change endlessly. By means of opinion box and anonymous mails, employees can deliver their suggestions and proposals to enterprises and help to establish better corporate culture. Apart from it, making suggestions and proposals can reinforce employees' sense of responsibility and help them integrate individual interest with corporate interest.

\section{In Social Terms}

1) Formulate Relevant Legislation:The legislature in our country should supplement and improve the Law of Labor, clarifying respective rights and obligations for both parties. According to new Law of Labor, trained employees who leave from jobs during period of service must assume legal liability under the condition that training charges have already incurred by sending employees to training organizations. However, this clause obviously neglects corporate internal training expenses such as professional ethics training and operational skill training which consume corporate resources. Consequently, The legislature should draft relevant law to protect legal rights of enterprises and employees.

2) Construct Punishment Mechanism:Human Resources and Social Security Department can construct sophisticated 
punishment mechanism to limit casual flow of staff. Flow of trained employees across different sectors and areas, to some degree, breaks regional and sectoral balance and impede development of these areas and enterprises, having a detrimental influence on corporate reputation. Tenure of employee archive with exhaustive training details and length of service period, like credit file, exerts negative effect for reemployment of employees who have records of casual flow after training. The information in employee archive should be upgraded regularly. Flow frequency of employees can be predicted by analyzing information about enterprises they work for and their locations. For an unstable employee who changes job and workplace frequently, the enterprise may be more meticulous in providing training.

\section{REFERENCES}

[1] Li Quansheng, Liu Hui. Analysis of causes and Countermeasures of enterprise the brain drain after training in china [J]. Xinjiang finance and economics, 2010.1

[2] TianEnShun, YangYaQing. Enterprise training risk and its prevention strategies [J].journal of human resources development, 2004, (8)

[3] YixinZhan. Enterprise human resources management risk research [D]. Changchun: Jilin university, 2011.5

[4] Amin Akhavan Tabassi , A.H. Abu Bakar. Training, motivation, and performance: The case of human resource management in construction projects in Mashhad, Iran. International Journal of Project Management 27 (2009) 471-480

[5] Arasanmi, Chris N. ; Wang, William Y.C.; Singh, Harminder; Ekundayo, Samuel . What motivates end-users to transfer gained knowledge from Enterprise Systems training? Pacific Asia Conference on Information Systems: Quality Research in Pacific, 2011 